\title{
PREDICTING SETTLEMENT OF CHEMICALLY STABILISED LANDFILLS
}

\author{
Behnam Fatahi ${ }^{1}$, Hadi Khabbaz ${ }^{2}$ \\ ${ }^{1,2}$ School of Civil and Environmental Engineering, University of Technology Sydney (UTS), NSW, Australia,
}

\begin{abstract}
This paper presents the findings of numerical analyses to predict the vertical and horizontal displacements of closed landfills under surcharge load with and without treatment by chemical admixtures. The finite element program, PLAXIS, has been used to evaluate the settlement of a landfill model. The soft soil creep model is used for this analysis. Five layers of solid waste are considered for the landfill to evaluate the effect of depth of stabilisation on settlement of landfill model. Treated and untreated municipal solid waste (MSW) parameters are obtained from the results of an extensive laboratory program performed on MSW samples in this research. The settlement of the landfill model 10 and 20 years after applying the surcharge load for different fly ash-quicklime contents and various depths of improvement is estimated. Results indicate that treatment of MSW reduces the vertical displacement of the landfill model under surcharge load significantly. This reduction is more with higher depths of improvement. The finite element results have been validated based on results of triaxial tests conducted in the laboratory on the treated municipal solid waste.
\end{abstract}

Keywords: Landfill, Settlement, Fly ash, PLAXIS

\section{INTRODUCTION}

Landfill design and construction technology has progressed rapidly during the past two decades in reaction to more strict controlling requirement and demands. However before any construction on top of landfills, properties of decomposed waste materials should be improved as required. Whether immediately or long time after construction, damage and cracks in structures are a challenging issue for organisation that design and construct foundations on improved landfill sites. Generally, clients require a maximum post construction settlement less than a certain value over the structure's life-time, and limit the differential settlement to a certain change in the grade.

\section{IMPROVEMENT TECHNIQUES}

The stabilisation of landfills and waste disposal sites for structural and environmental purposes has been performed through the application of current soil stabilisation and ground improvement techniques. The deep dynamic compaction (DDC) technique is a common ground improvement technique due to its relatively economical and easy application. The deep dynamic compaction technique has been carried out with success in a large range of soils including MSW. Reference [1] reviewed 64 case histories regarding the effectiveness of the DDC on MSW landfill sites. Their results indicated that the depth of improvement is smaller in MSW compared to cohesionless soils. In addition, the settlement caused by DDC depends on the applied energy and it is in the range of $5 \%$ to $25 \%$ of the MSW thickness. With deep dynamic compaction large voids reduce and afterward other technique such as fly ash-lime grouting can further reduce the remaining smaller voids. Moreover, the lime/fly ash slurry injection has significant effects on protecting groundwater, neutralising leachate, and for placing curtain walls to prevent leachate migration. Replacement of cement with by-product materials such as fly ash can decrease the stabilisation expenses. Many researchers reported the application of fly ash in geotechnical projects (e.g. [2]-[4]). According to [5], from an economic and environmental viewpoint, rich materials in slaked lime $\left(\mathrm{Ca}(\mathrm{OH})_{2}\right.$, calcium hydroxide), can be treated together with pozzolanic materials, such as fly ash, to develop a cementitious material.

\section{ACTIVATION OF FLY ASH WITH LIME}

The reaction of fly ash (FA) with lime results in an immediate improvement of the soil's mechanical properties during stabilsation. It reduces the moisture content of the soil, which has a fast stabilising effect, increases soil $\mathrm{pH}$, preparing a condition for secondary pozzolanic reactions and also it produces heat, which accelerates the chemical reactions [6]. Many activation methods have been suggested by researchers to treat unstable soils with fly ash. The 
main purpose of these efforts was to improve the reactivity of the pozzolan, in order to enhance the mechanical and stability characteristics of the mixed product. Extended grinding proposed by [7], curing at high temperatures suggested by [8], alkali activation considered by [9] and [10] and chemical activation procedures presented by [11] are some approaches, which have been practiced to attain that goal.

\section{FINITE ELEMENT MODELING}

The finite element program PLAXIS version 9 has been used to evaluate the settlement of stabilised landfill. The cross-section utilised for the numerical analysis is presented in Fig.1. Five layers of solid waste were considered for the landfill to estimate the effect of depth of stabilisation on landfill settlement. All the dimensions for model are given in Fig.2. Accordingly, the solid waste properties need to be adjusted to consider various improvement options. The landfill is modeled as a two dimensional plane strain model.

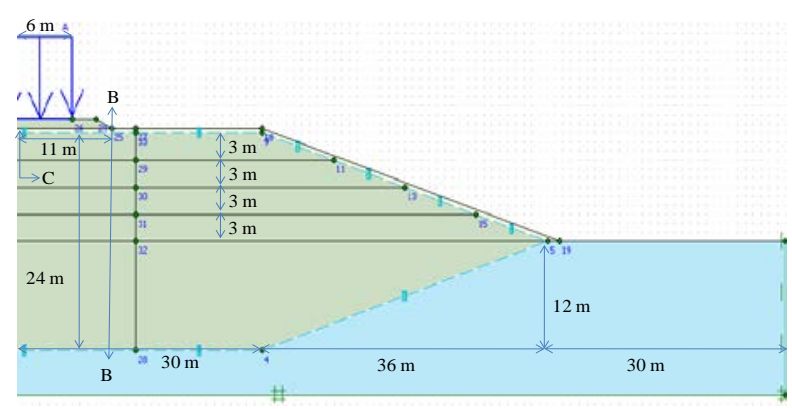

Fig.1 Dimensions of the model.

\subsection{Mesh Generation and Boundary Conditions}

The 15 nodded triangle elements were employed powerful 15-node element provides an accurate calculation of stresses and failure loads. The two vertical boundaries on both sides are free to move in vertical direction, whereas the horizontal boundary at the base is considered to be fixed in both vertical and horizontal directions as presented in Fig.1. The foundation soil was considered to be stiff soil and its stability and deformation were not considered directly in this analysis. Cross-sections of generated mesh have been shown in Fig.4.

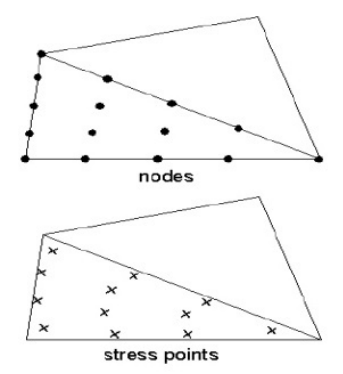

Fig.3 The 15-nodded triangle elements used in modeling.

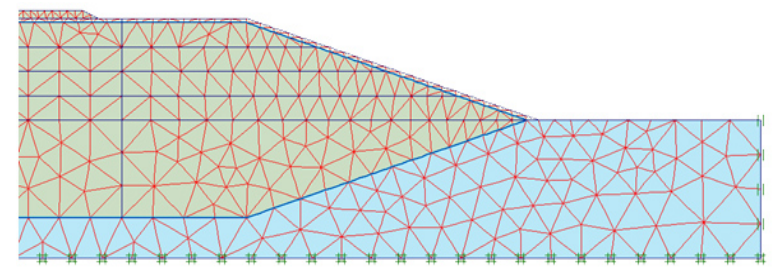

Fig.4 Cross-section of generated mesh.

\subsection{Adopted Material Models}

All soils exhibit some creep, and primary compression is thus always followed by a certain amount of secondary compression. The secondary

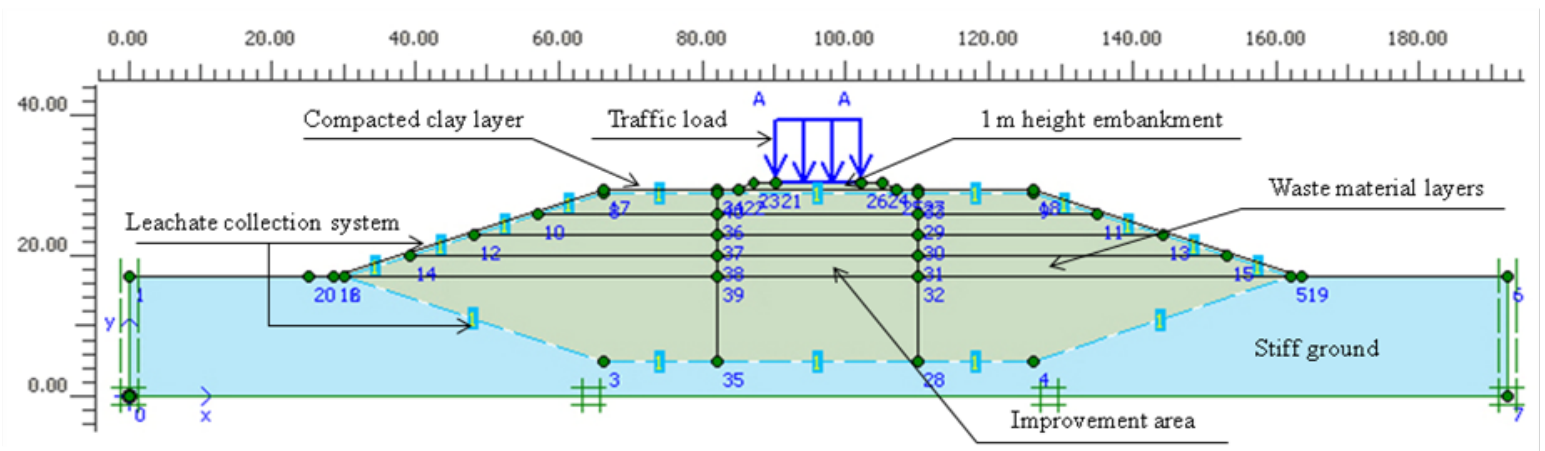

Fig.2 Cross-section of the numerical model.

in the modeling as shown in Fig. 3 and the mesh generation algorithm of PLAXIS version 9.0 was used in this study. It provides a fourth order interpolation for displacements and the numerical integration involves twelve stress points. The compression (for instance during a period of 10 or 30 years) can be a certain percentage of the primary compression. This is for instance the case when constructing embankments over closed landfill sites. Indeed, the primary settlement of footings and 
embankments are usually followed by a substantial creep settlement in later years. In such cases it is desirable to estimate the creep from FEMcomputations. The soft soil creep model was used for this analysis due to several characteristics such as:

- Stress-dependent stiffness

- Distinction between primary loading and unloading-reloading

- Secondary compression

- Memory of pre-consolidation stress

- Failure behaviour according to the MohrCoulomb criterion

\subsection{Material Parameters}

Municipal solid waste parameters used in FEM analysis for different contents of stabiliser are presented in Table 1. In addition, parameters used for compacted clay as a cover layer of closed landfill model and road embankment are summarised in Table 2.

Some of the important waste properties required for the analyses are the unit weight, the shear strength, the permeability, the primary compression index and the secondary compression index. These parameters were obtained from the results of the extensive laboratory program performed on the MSW samples. The unit weight of solid waste is an important factor in evaluating the settlement of landfills. The unit weight values of MSW specimens changed slightly for specimens mixed with different fly ash-quicklime (QL) contents.

The results obtained from consolidated drained (CD) triaxial tests confirmed that the shear strength parameters are strongly influenced by the fly ashquicklime content mixed with MSW. The shear strength parameters of solid waste estimated in this study at different fly ash-quicklime content also presented in Table 1 . It reveals that $c$ and $\varphi$ values of MSW specimens increased with increasing the fly
Moreover, from consolidation test performed it has been demonstrated that the value of $\mathrm{C}_{\mathrm{c}}$ decreased by $30 \%$, when the fly ash-quicklime content increased from 0 to $26.7 \%$. By increasing the fly ashquicklime content, the treated specimens indicated more resistance against the compressive loading and less compressibility characteristics. Furthermore, the creep results clearly shows that the value of the secondary compression index, $\mathrm{C}_{\alpha}$, for MSW specimens decreased from 0.052 to 0.033 , while fly ash-quicklime content increased from 0 to $26.7 \%$. This means that, for any given time period, the volume change during secondary compression is more for untreated specimens than treated with fly ash-quicklime. Hence, fly ash-quicklime admixture is effective in reducing the volume change during the primary consolidation as well as the secondary consolidation. The corresponding values for the compression index and the secondary compression index are also reported in Table 1.

\subsection{Analysis Type}

The settlement of proposed landfill model in PLAXIS was computed using 'consolidation analysis' as a calculation type and 'staged construction' as a loading input. Based on Table 3 the effects of various fly ash-quicklime contents and different depths of improvement were examined. The model presents 30 years old closed landfill and selected MSW materials are decomposed waste. In the first stage of modelling, the filling process of landfill was completed in 4 stages (each stage consisted of 4 metres over 30 days). After filling the site with decomposed waste material, in landfill model, the waste was then covered with a $0.5 \mathrm{~m}$ layer of compacted clay. After this the model evaluated the settlement of the landfill after 30 years of self weight of MSW. In the next stage a $1 \mathrm{~m}$ thick road embankment was constructed on the closed landfill

Table 1 Parameters for soft soil creep model in FEM analysis

\begin{tabular}{ccccccccc}
\hline $\begin{array}{c}\text { FA-QL } \\
\text { Content } \\
\%\end{array}$ & $\begin{array}{c}\text { Unit } \\
\text { weight } \\
\gamma_{\mathrm{sat}} \\
\mathrm{kN} / \mathrm{m}^{3}\end{array}$ & $\begin{array}{c}\text { Void } \\
\text { ratio }\end{array}$ & $\begin{array}{c}\text { Cohesion } \\
\mathrm{C} \\
\mathrm{kN} / \mathrm{m}^{2}\end{array}$ & $\begin{array}{c}\text { Friction } \\
\text { abgle } \\
\varphi^{\mathrm{o}}\end{array}$ & $\begin{array}{c}\text { permeability } \\
\mathrm{K} / \text { day }\end{array}$ & $\begin{array}{c}\text { Recompression } \\
\text { index } \\
\mathrm{c}_{\mathrm{r}}\end{array}$ & $\begin{array}{c}\text { Compression } \\
\text { index } \\
\mathrm{c}_{\mathrm{c}}\end{array}$ & $\begin{array}{c}\text { Secondary } \\
\text { compression } \\
\text { index } \\
\mathrm{C}_{\alpha}\end{array}$ \\
\hline $0 \%-0 \%$ & 14.6 & 0.63 & 11 & 29 & 0.012 & 0.075 & 0.33 & 0.052 \\
$5 \%-1.7 \%$ & 14.8 & 0.61 & 20 & 33 & 0.0092 & 0.07 & 0.29 & 0.045 \\
$10 \%-3.3 \%$ & 15 & 0.59 & 26 & 36 & 0.0088 & 0.068 & 0.28 & 0.04 \\
$15 \%-5 \%$ & 15.2 & 0.57 & 29 & 38 & 0.0088 & 0.064 & 0.24 & 0.036 \\
$20 \%-6.7 \%$ & 15.4 & 0.56 & 30 & 39 & 0.0082 & 0.061 & 0.23 & 0.033 \\
\hline
\end{tabular}

ash-quicklime content to MSW specimens.

In addition, the results from permeability tests indicated that with an increase in fly ash-quicklime content in the MSW specimen, the coefficient of permeability reduced. The corresponding numbers presented in Table 1. model over a 6 month period, and then a traffic loading of $20 \mathrm{kPa}$ with a reduction factor of 0.5 was applied on to the road embankment. In the final step, the vertical and horizontal displacement of the landfill model 10 and 20 years after applying the traffic load 
for different amounts of fly ash-quicklime and various depths of improvement were calculated.

\section{RESULTS AND DISCUSSION}

\subsection{Vertical Settlement 10 Years after Applying Traffic Load}

The results of the numerical predictions of the model were estimated in PLAXIS. Table 3 presents the vertical displacements of the landfill model 10 years after applying the traffic load at the midpoint below the embankment. These numbers reported based on different depths of treatment and various fly ash-quicklime contents.

The results predicted that the vertical settlement of untreated landfill model is about $370 \mathrm{~mm} 10$ years after applying traffic load. In addition, the result illustrated that treating MSW with fly ash-quicklime reduced the vertical displacement of the model significantly. This reduction is more with higher depths of improvement. It revealed that for $3 \mathrm{~m}$ improved landfill with $26.7 \%$ fly ash-quicklime the vertical settlement reduced $20 \%$ (from $370 \mathrm{~mm}$ to 296 $\mathrm{mm})$ and this reduction for $6 \mathrm{~m}, 9 \mathrm{~m}, 12 \mathrm{~m}$ and $24 \mathrm{~m}$ improved landfill was 32\%, 40\%, $46 \%$ and 58\%, respectively.

Table 2 Model parameters used for cover layer and road embankment.

\begin{tabular}{ccccccc}
\hline ID & $\begin{array}{c}\gamma_{\mathrm{t}} \\
\mathrm{kN} / \mathrm{m}^{3}\end{array}$ & $\begin{array}{c}\mathrm{c} \\
\mathrm{kPa}\end{array}$ & $\varphi^{\mathrm{o}}$ & $\psi^{\rho}$ & $\begin{array}{c}\mathrm{E} \\
\mathrm{kPa}\end{array}$ & $v$ \\
\hline Cover & 17.5 & 10 & 25 & 0 & $2.5 \mathrm{E} 4$ & 0.35 \\
Road & 18 & 5 & 30 & 5 & $6.5 \mathrm{E} 4$ & 0.3
\end{tabular}

\subsection{Vertical Settlement 20 Years after Applying the Traffic Load:}

The outcomes of the numerical estimation of the model are predicted in PLAXIS. Table 4 shows the vertical displacement of the landfill model 20 years after applying the traffic load at the midpoint below the embankment. These numbers are based on different depths of treatment and various amounts of fly ash-quicklime. The results showed that the settlement of the untreated landfill model is about 536 mm 20 years after applying traffic load. Moreover, these result indicated that treatment of MSW with fly ash-quicklime reduced vertical displacement of the model significantly, and this reduction was more for higher depths of improvement. It showed that 20 years after applying traffic load on 3m improved landfill with $26.7 \%$ fly ash-quicklime the vertical settlement reduced by $19 \%$ (from $536 \mathrm{~mm}$ to 444 $\mathrm{mm}$ ) and this reduction for $6 \mathrm{~m}, 9 \mathrm{~m}, 12 \mathrm{~m}$, and $24 \mathrm{~m}$ improved landfill is $29 \%, 37 \%, 43 \%$, and $55 \%$, respectively.

Furthermore, Fig. 5 and Fig. 6 indicate the effects that the amounts of fly ash-quicklime have on the vertical displacement versus time for $3 \mathrm{~m}$ and $9 \mathrm{~m}$ improvement depths at the midpoint below the embankment. These figures clearly indicated that increasing the amount of fly ash-quicklime reduced vertical settlement to a large extent. It can also be inferred that increasing the depth of improvement significantly decreases vertical settlement in model.

Table 3 Vertical displacement of the landfill model 10 years after applying traffic load.

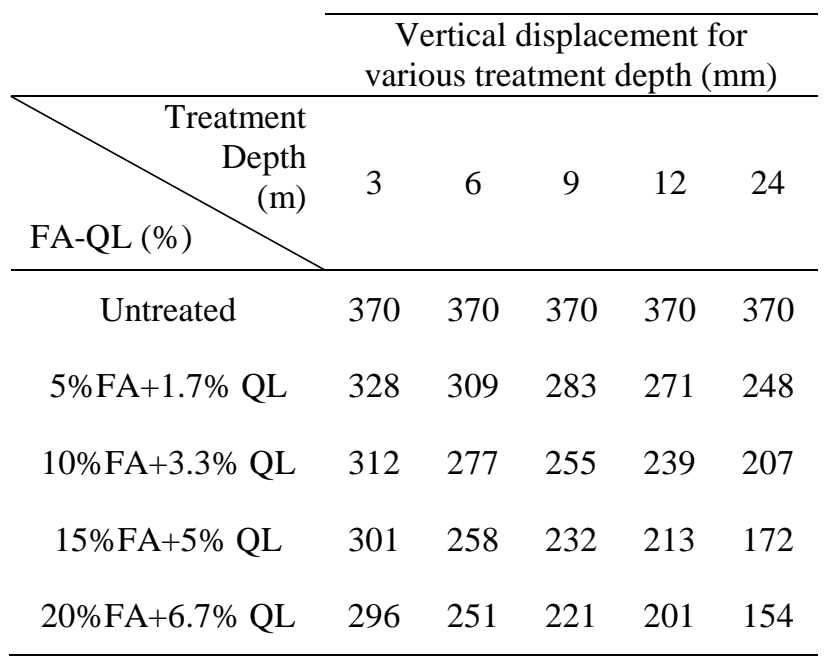

Table 4 Vertical displacements of the landfill model, 20 years after applying the traffic load.

\begin{tabular}{lcccccc} 
& \multicolumn{5}{c}{$\begin{array}{c}\text { Vertical displacement for various } \\
\text { treatment depth (mm) }\end{array}$} \\
\hline $\begin{array}{r}\text { Treatment } \\
\text { Depth }\end{array}$ & 3 & 6 & 9 & 12 & 24 \\
\hline FA-QL (\%) & 536 & 536 & 536 & 536 & 536 \\
10\%FA+1.7\%QL & 486 & 451 & 426 & 408 & 372 \\
15\%FA+5\% QL & 451 & 394 & 356 & 327 & 262 \\
20\%FA+6.7\%QL & 444 & 383 & 339 & 308 & 244
\end{tabular}

\subsection{Horizontal Displacement 10 Years after Applying the Traffic Load}

The result showed that the treatment of MSW with fly ash-quicklime reduced the maximum horizontal displacement of the model, and this reduction was 
more for higher depths of improvement. Figure 7 shows the horizontal displacement versus depth for landfill treated with $26.7 \%$ fly ash-quicklime with various depths of improvement in a section below the toe of embankment. It can be seen that at any specific depth below the toe of embankment, with increasing depth of improvement, the horizontal displacement was reduced and maximum horizontal displacement occurred at higher depths. Moreover, Fig.8 shows the horizontal displacement versus depth for $9 \mathrm{~m}$ improved landfill treated with various amounts of fly ash-quicklime below the toe of embankment. This proves that increasing the amount of fly ashquicklime reduced the horizontal displacement at any specific depth, and also that maximum horizontal displacement occurred at higher depths.

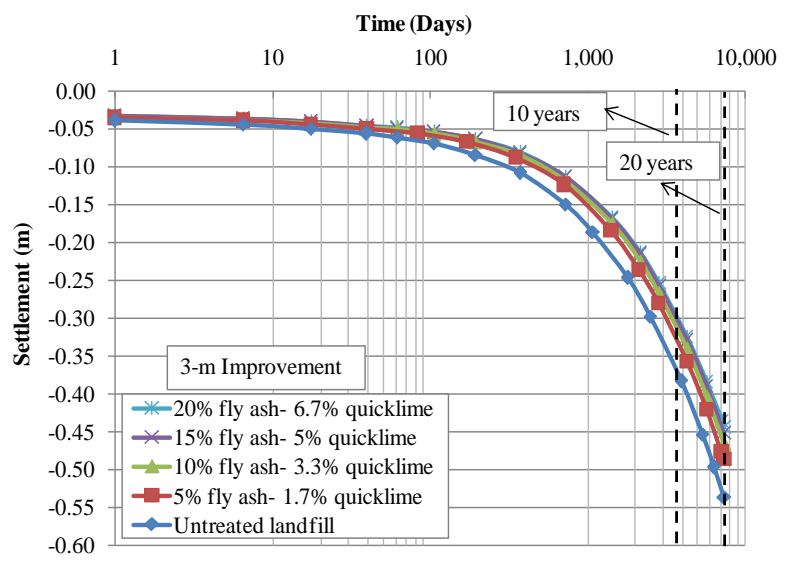

Fig.5 Vertical settlement versus time for 3-m improved landfill.

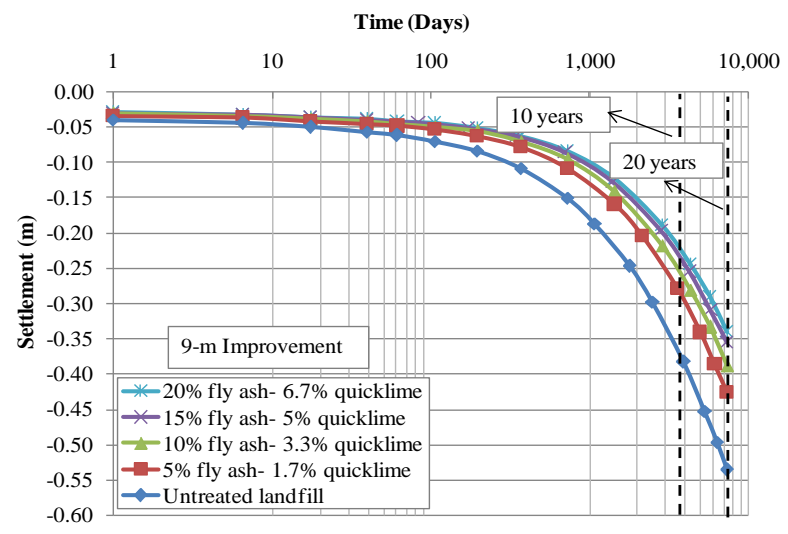

Fig.6 Vertical settlement versus time for 9-m imroved landfill.

\section{VALIDATION}

Finite element results are validated based on results of triaxial tests conducted in the laboratory on the treated MSW. Finite element analysis of triaxial model (for treated MSW treated with 15\% fly ash $+5 \%$ quicklime and dimensions of $100 \mathrm{~mm}$ height and $50 \mathrm{~mm}$ diameter) was carried out using PLAXIS 2D. The problem was considered as an axi-symmetry model and the nodes on left vertical boundary was restricted to displace horizontally (horizontal fixity) but allowed to undergo vertical displacement whereas all the displacements of the nodes at the bottom surface was arrested (total fixity). A typical axisymmetric model under triaxial loading condition is shown in Fig.9. The treated MSW material was simulated with soft soil creep model with 15 node triangular elements. The material properties used in the finite element analysis are given in Table 1.

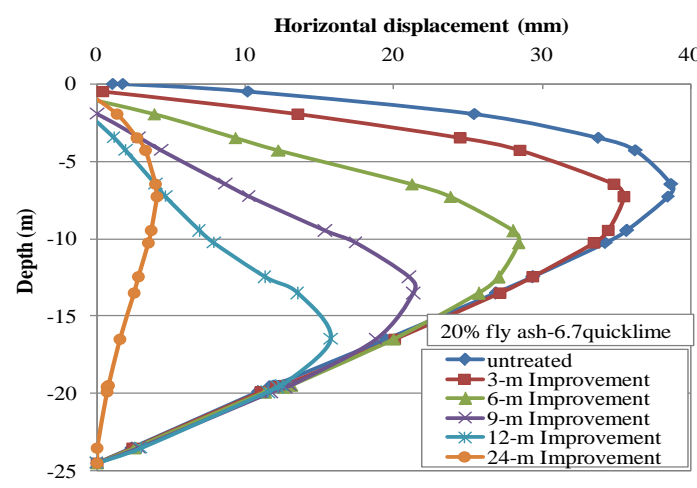

Fig.7 Horizontal displacement versus depth for the landfill treated with $26.7 \%$ fly ash-quicklime content.

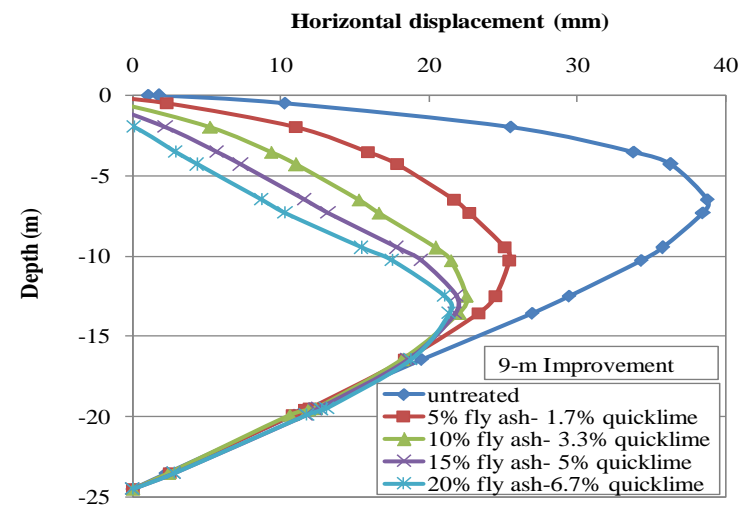

Fig.8 Horizontal displacement versus depth for 9-m improved landfill.

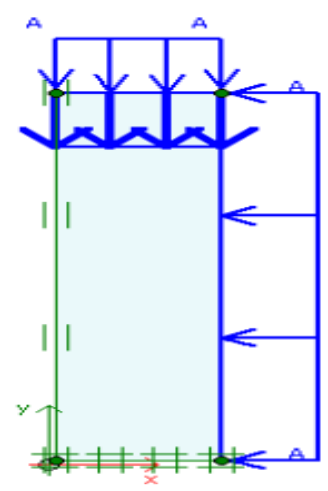

Fig.9 Typical axisymmetric geometry model. 
Figure 10 shows the comparison between the laboratory measurement and finite element predictions. As indicated the selected soft soil creep model (which is based on modified cam-clay model) incorporated in the finite element solution, results in reasonable agreement between the measurements and predictions.

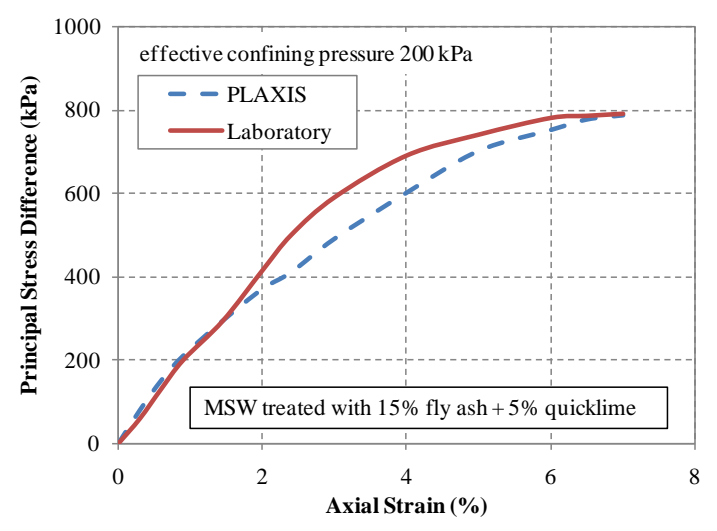

Fig.10 Comparison between the laboratory measurements and finite element predictions.

\section{CONCLUSIONS}

A finite element program, PLAXIS version 9, was used to evaluate the settlement of the landfill model under traffic load, with and without treatment by fly ash-quicklime. The soft soil creep model was used for this analysis. Five layers of solid waste were used for the landfill model to evaluate how the depth of stabilisation affected the vertical and horizontal displacement of the model. Treated and untreated MSW parameters used for the model were obtained from the results of the extensive laboratory program performed on treated and untreated MSW samples. The vertical and horizontal displacement of the landfill model 10 and 20 years after applying the traffic load, and with different amounts of fly ashquicklime and various depths of improvement, were estimated. The results of the model analyses with PLAXIS showed that treating MSW with fly ashquicklime reduced the vertical displacement under traffic load at the midpoint below the embankment. Horizontal displacement of the landfill model at a specific depth in a section below the toe of the embankment under traffic load was also significantly reduced. These reductions in vertical and horizontal displacement were greater with higher depths of improvement. For 3m improved landfill with $26.7 \%$ fly ash-quicklime, the vertical settlement 10 years after applying traffic load below the embankment was reduced 20\% (from $370 \mathrm{~mm}$ to $296 \mathrm{~mm}$ ) and this reduction for $6 \mathrm{~m}, 9 \mathrm{~m}, 12 \mathrm{~m}$ and $24 \mathrm{~m}$ improved landfill was $32 \%, 40 \%, 46 \%$ and $58 \%$, respectively.

\section{REFERENCES}

[1] Zekkos D, Flanagan M (2011) Case Historiesbased Evaluation of the Deep Dynamic Compaction Technique on Municipal Solid Waste Sites. Geo-Frontiers, pp 529-538

[2] Kawasaki T, Niina A, Saitoh S, Suzuki Y, Honjo Y (1981) Deep mixing method using cement hardening agent. Proc 10th Int Conf on Soil Mechanics and Foundation Engineering, Southeast Asian Geotechnical Soc Bangkok, pp 721-724

[3] Kitazume M, Yamazaki H, Tsuchida T (2000) Recent soil admixture stabilization techniques for port and harbor constructions in Japandeep mixing method, premix method, lightweight method. ProcInt Seminar on Geotechnics in Kochi, ISGK 2000, Kochi, Japan, pp 23-40

[4] Kehew EA (1995) Geology for engineers and environmental scientists, $2^{\text {nd }}$ edn. Prentice Hall, Englewood Cliffs, pp 295-302

[5] Horpibulsuk S, Phetchuay C, Chinkulkijniwat A (2012) Soil stabilization by calcium carbide residue and fly Ash. J Mater Civil Eng 24(2):184-193

[6] Janz M. Johansson S (2002) The function of different binding agents in deep Stabilization. Svenskdjup stabilisering Report 9

[7] Bouzoubaa N, Zhang MH, Bilodeau A, Malhotra VM (1997) The effect of grinding on the physical properties of fly ashes and a Portland cement clinker. CemConcr Res 27(12):1861-1874

[8] Shi C, Day RL (1993) Acceleration of strength gain of lime-pozzolan cements by thermal activation. CemConcr Res 23(4):824-832

[9] Palomo A, Grutzeck MW, Blanco MT (1999) Alkali-activated fly ashes; a cement for the future. CemConcr Res 29 (8):1323-1329

[10] Xie Z, Xi Y (2001) Hardening mechanisms of an alkaline-activated class $\mathrm{F}$ fly ash. CemConcr Res 31(9):1245-1249

[11] Shi C, Day RL (1995) Acceleration of the reactivity of fly ash by chemical activation. CemConcr Res 25(1):15-21

Int. J. of GEOMATE, Dec, 2013, Vol. 5, No. 2 (Sl. No. 10), pp. 700-705.

MS No. 3339 received on June 14, 2013 and reviewed under GEOMATE publication policies. Copyright (C) 2013, International Journal of GEOMATE. All rights reserved, including the making of copies unless permission is obtained from the copyright proprietors. Pertinent discussion including authors' closure, if any, will be published in the Dec. 2014 if the discussion is received by June, 2014.

Corresponding Author: Behnam Fatahi 